\title{
Early Childhood Education (ECE) in South Africa: Black student teachers' views on push and pull forces in their training
}

\section{Miemsie Steyn}

Department of Early Childhood

Faculty of Education

University of Pretoria

\section{Cycil Hartell}

Centre for Japanese Studies

University of Pretoria

\section{Teresa Harris}

Department of Childhood Studies

James Madison University

Harrisonburg

USA

\begin{abstract}
Although the Black student population in South Africa now amounts to $72 \%$ of student enrolments in higher education, the same trend is not experienced in early childhood education (ECE). Research suggests that cultural and linguistic differences between home communities and university settings as well as meeting the academic demands of an institution that is unfamiliar with students' home languages and cultures can be overwhelming. Using the Force Field Model of Professional Development as a theoretical lens, the experiences of Black students are explored at a previous White university. Findings from focus group interviews indicate that financial restraints, unfamiliar teaching practices and language barriers are amongst the factors that are experienced as barriers and could serve as reasons for the low enrolment in ECE.
\end{abstract}

\section{Keywords}

Barriers to choosing ECE, Black students, student diversity, early childhood education, push and pull factors

\section{INTRODUCTION}

In South Africa, as in many other countries around the world, the short supply of teachers increasingly becomes a challenge to providing quality education to all (Arends \& Phurutse, 2009). Early Childhood Education (ECE) is affected more severely by this; 
and it is generally recognized that there is a serious shortage of well-trained, qualified teachers at this level. Compounding the problem, universities in South Africa experience a very low enrolment rate of Black students in foundation phase education programmes. Subsequently, the increasingly diverse classrooms have teachers who are from different cultural and ethnic backgrounds to the majority of the schooling population. It follows that Black learners from diverse cultural, ethnic backgrounds, whose home languages are not the language of instruction in the schools, do not see teachers who look like them or sound like them or understand the contexts from which they come. If it is important for teachers to be able to connect with their learners, and to employ teaching methods that are relevant so that all learners can become successful in their academic pursuits, then we must carefully examine the factors that invite and exclude potential Black teachers from the profession.

In this study we attempted to answer the question, "What are the academic experiences of Black South African students in Early Childhood Education (ECE) at a former White university?", as part of a larger project to examine the recruitment and retention of Black students in Early Childhood Education. For the purposes of this article, ECE refers to the education of young children from birth to 9 years. In South Africa, this corresponds with what is often referred to as Early Childhood Development (ECD) for children from birth to 5 years in families, and early childhood institutions, and for children from 5 to 9 years, accommodated in the Foundation Phase (Grades R-3) of schooling. We also refer to 'Black learners/students' as all the African Language speaking students who participated in this study identified themselves as Black South Africans.

\section{LITERATURE REVIEW}

Following the first democratic elections of 1994, South Africa underwent political as well as educational reform. The latter attempted to "provide a system of education that builds democracy, human dignity, equality and social justice" (Department of Education, 2001) with its primary aim to broaden participation in higher education so as to reduce the highly stratified race and class structure of the country (Fraser \& Killen, 2005). Subsequently, higher education institutions in South Africa encountered remarkable 
changes in structuring, funding and student numbers (Gbadamosi \& De Jager 2009:871). Former White universities, known for their high standards and academic excellence, experienced an influx of Black students who were previously excluded from these institutions. This widened access resulted in an increased enrolment of Black students that now accounts for over $72 \%$ of enrolments in higher education (Brüssow, 2007). Although there is a significant increase in the Black student population, the same trend is not experienced in teacher training, particularly in Early Childhood Education.

South Africa's problem with recruiting more Black students into primary education is part of an international challenge (Santoro, 2007). According to 2007 figures, little change in the demographics of teachers has occurred since 2000, and little growth is reported in the number of students entering teacher education programmes (Planty, Hussar, Snyder, Kena, Ramani, Kemp, Bianco, \& Dinkes, 2009). In the United Kingdom, Basit, McNamara, Roberts, Carrington, Maguire and Woodrow (2007:280) noted that "the under-representation of some ethnic groups in the teaching profession continues to present a challenge both to policy-makers and schools". Santoro (2007) further pointed out that one in four Australians has a first language that is not English.

But does it matter that there are so few Black teachers in the ECE classrooms in SA? Robinson, Paccione and Rodriquez (2003:202) believe that Black teachers play a critical role in the lives of all learners, serving to dispel the "myth of racial and ethnic inferiority in the minds of White students and students of color" and promoting positive cultural understandings in racially mixed schools by serving as "cultural brokers" for the growing number of diverse learners. The National Education Association (2002) pointed out that there is evidence that when Black teachers were present there were greater gains for Black learners, fewer placements in special education, decreased absenteeism, greater involvement in school activities, and increased parental involvement. With regards to Black learners in particular, being taught by a teacher who had direct experience of being a member of the same ethnic group helped them, because these teachers understood the importance of academic achievement from this particular perspective (Robinson et al., 2003). Santoro (2007) contributes by referring to 
the Australian example. Although the dominant academic culture in Australia is White Anglo-Australian, which also constitutes the largest race group, the South African situation is different. Here the government is run by the dominant race group, but the academic culture still remains westernized; an inheritance of the Apartheid regime. While being different, the Australian example could be used didactically to help us understand the South African situation, when saying that teachers from marginalized backgrounds utilise "their knowledge of self to empathize with their minority students, contextualize their students' responses to schooling through an understanding of their lives beyond school and to 'come to know' them from perspectives unavailable to White Anglo-Australian teachers" (Santoro, 2007:84).

Yet the student enrolment in teacher education programs, particularly in ECE, at South African universities remains predominantly White, middle class, and female and there are few signs that this is changing (NCES, 2010). Robinson, et al. (2003) point out that in the United States, the under-representation of Black teachers reflects the broader array of opportunities and incentives to enter other fields. In South Africa we find that with academically successful students, not only are the opportunities enhanced, but their own communities support their decisions to enter more prestigious careers (Crosser, 2009). For economically disadvantaged students, the challenges of accessing sufficient financial assistance, bursaries paying out too late, challenges with accommodation, and the institutional barriers, such as language and cultural alienation further disadvantage potential candidates (Steyn, Harris, \& Hartell, 2012).

There are personal costs for Black students as well. Sedlacek (1999) explains that cultural and linguistic differences between home communities and university settings can be overwhelming, and students often experience a conflict of interest between personal educational goals and familial responsibilities. In a previous study, Steyn, Harris and Hartell (2012) also found that students faced ridicule from their peers who view teaching as a worthless career. Students also reported that their own teachers discouraged them from entering a profession that is overworked, underpaid and criticised in the media. Additional barriers students must face, once they are enrolled in 
the university itself, include meeting the academic demands of an institution that is unfamiliar with the students' home languages and cultures, which creates another academic challenge (Meacham, 2000; Sedlacek, 1999; Sennet, Finchilescu, Gibson, \& Strauss, 2003). Compounding the challenges within the educational context itself, Black students must also form relationships with predominantly White lecturers and peers who may overtly or unintentionally reflect racial biases (Davis, Dias-Bowie, Greenberg, Klukken, Pollio, Thomas, \& Thomas, 2004; Kornfield, 1999).

So why do Black students enter Early Childhood Education? Our study forms part of a research project on the recruitment and retention of Black students in Early Childhood Education at higher institutions. In this article the spotlight falls on the possible factors which play a role in the decision of Black students to either pursue or avoid studies in this teaching phase. We regarded the Force Field Model of Professional Development (Samuel \& Van Wyk, 2008) as an appropriate theoretical and practical point of departure, as it endeavours to explore the internal and external forces which influence the student teacher's identity. As Samuel and Van Wyk (2008:140) aptly remark: "The journey to becoming professional teachers is [thus] characterised by many pushes and pulls in different directions." For the purpose of this study, the model will be utilised to determine the forces that influence Black student teacher's experiences within the Early Childhood Education programme and which may shed light on the reasons for the low rate of enrolment in this programme.

\section{FORCE FIELD MODEL OF PROFESSIONAL DEVELOPMENT}

Although this model sets out to explore the factors that impact on the professional development of student teachers, it can also be used to determine which forces influence the experiences of student teachers in a specific programme. The Force Field Model uses the analogy of an electron in a charged forced field where it is being "pulled and pushed" by various forces (Samuel \& Van Wyk, 2008:140). With reference to our study, this model sets out to explain different forces that may determine the experiences of Black students in the ECE programme and which subsequently may attract or deter the decision to enter ECE as a potential career. Samuel and Van Wyk (2008) mention 
the following categories in which these forces can manifest: biographical, institutional, programmatic and contextual. "These forces are both internal and external to the individuals themselves and constitute forces from their lived experiences, theoretical conceptions exposed in their training programmes, the macro-contextual forces of policy influencing teacher identity, and the specific world of practices in unique schooling sites" (Samuel \& Van Wyk, 2008:140).

We furthermore chose this framework to give a voice to the Black students within Early Childhood Education at a former White university as a way to explore their experiences in the programme and to determine the institutional strengths as well as the obstacles these students face that marginalized and impeded their progress. Our goal was to identify those barriers that should be removed in order to attract more Black students into ECE.

The Force Field Model provided the framework for us to determine how the Department of Early Childhood Education supported Black students in becoming successful educators; but also to identify the barriers which may be present within the department and which may marginalise these students. Although the composition of the department, at the time of this study, was $20 \%$ Black African language staff members and $80 \%$ White, all of the lecturers had previously worked in school contexts that served Black learners in early childhood settings and brought those experiences into their modules.

\section{METHODOLOGY}

The purpose of this study was to determine the experience of Black students in the ECE programme at the University of Pretoria. We invited all Black Early Childhood students (from first to third year of study) to participate in small group interviews.

Prior to the beginning of this study we met with Black students representing all the different phases, ECE through to Further Education and Training (FET), to gain their perspectives on students' decisions to study teaching. One of us visited several of the 
ECE classes as a guest speaker and met a number of the students informally as they talked with their lecturers between classes or during consultation hours. We shared the goal of learning directly from the students about their lived experiences as ECE students, and we stated to the students that we wanted to provide them with an opportunity to share their experiences as members of the department of ECE, and also as young adults who had lives outside the university that influenced their experiences as future teachers. It is through the stories of these students that we seek to understand their experiences and examine the voices of these students as a step towards undoing the barriers within the programme.

We hypothesized that the reason why so few Black students choose ECE for their teaching preparation may be due to institutional factors, such as high programme costs and a culturally distant or irrelevant curriculum. We wanted to find out from the students how they experienced the institution and the ECE programme by using The Force Field Model as our point of departure as it also offers the opportunity for the voice of participants to "uncover, challenge and expose" (Giles \& Hughes, 2009:689) practices which are perceived as excluding.

We chose a narrative approach because it allows sharing a story with those who are willing to listen. According to Gomez (1997:195), "Narrative inquiry is a methodological approach of understanding people's representations of the world, their actions in it, through the stories they tell". In our effort to understand why these students "think and act as they do in the situated contexts in which they live and labour" (Gomez, 1997:195), we brought students who were already enrolled in the same modules together to talk about their experiences in the ECE programme. Through our interview questions, we attempted to begin a conversation, listening to the students' stories as they shared their experiences of being Black South African students in a predominantly White Early Childhood teacher education program, and allowing them to lead the interview as they shared stories among themselves in response to questions we asked. We recognized that there was a significant power difference between White lecturers and Black students, and realized that much of what they had to share might reflect what 
they thought we wanted to hear. As themes emerged we talked with the two Black lecturers in the department to compare what we heard with their own experiences and conversations with the students.

\subsection{Participants}

At the time of the interviews only $1 \%$ of the students enrolled in the ECE programme were Black. There were 21 Black students, all female, enrolled in years one to three of the programme; 12 students participated in the interviews, three first-year students, five second year students, and four third year students. All of these students were female and all volunteered to participate in this study. The students came from rural as well as urban areas. Some of the students attended local schools in their home communities, while other students attended multiracial schools. Family socio-economic status varied among the students who participated in the interviews; however, all the students studied with bursaries.

\subsection{Data Collection}

One of us visited the ECE classes to talk about this research project and followed up with personal phone calls to the students to invite them to participate and arrange a time that was convenient for them. All interviews were held on campus in the building where students attended lectures at times that were identified by the students to accommodate their schedules. At the beginning of each interview session, students were reminded of the purpose of the interview and asked their consent for the interview to be audiotaped.

Semi-structured interviews that ranged from 60-90 minutes each were conducted with the students by both authors. We interviewed three first year students as one small group, the five second year students as a second group, and the two third year students as the third group. Questions addressed students' reasons for selecting the university under study and the Early Childhood Education programme, the support and challenges they received from their families and home communities, the support and barriers they experienced as university students in general and as students in the ECE programme in particular. All interviews were recorded and transcribed for analysis. 
The university under study approved this study through its formal Ethics' Committee. We maintained an ethical stance in interviewing students in ways that were positive for them by inviting them to meet with us in small groups of their own choice in places on campus that were convenient for them. We recognized that the information we gained as researchers could take advantage of our positions of power over them, so we attempted to be clear that we would maintain confidentiality throughout the research process (Seidman, 2006).

\subsection{Data analysis and discussion}

The interviews were transcribed and then read and coded line by line by each researcher. Codes were compared between the researchers and to the research literature, and then refined to identify emerging themes. Five broad themes emerged: (a) differences in educational experiences, (b) differences in language, (c) experiences in the ECE programme, (d) costs and (e) conflicting concepts of teaching/learning. These themes constitute forces that are both internal and external to the individuals themselves and were a perfect fit for the categories identified in the Force Field Model. The following table highlights the relationship between the themes (forces) and categories as identified by Samuels and Van Wyk (2008). The data will be discussed accordingly.

Table 1. Findings according to the Force Field Model (Samuel and Van Wyk, 2008).

\begin{tabular}{|ll|}
\hline Categories & - Differences in educational experiences \\
\hline Biographical Forces & - Differences in language \\
Programmatic Forces & - Experiences in ECE \\
Contextual Forces & - Costs \\
Institutional Forces & - Conflicting concepts of teaching/learning \\
\hline
\end{tabular}

\subsubsection{Biographical Forces}

Samuel and Van Wyk (2008: 140,141) explain biographical forces as "...including the different individual's cultural, racial, ethnic and religious identities which predispose 
them to think, act or behave in particular ways with learners, school authorities and with school subjects". This particular category can be regarded an internal force, as it forms part of the individual's culture and background.

\subsubsection{Differences in educational experiences}

In the context of this study, this internal force constitutes the experiences of Black students with preschool education in their home communities. It was their prior experiences that the students brought with them into their university classrooms. When lecturers began to describe early childhood settings, activities, and materials, Black students were challenged to understand what the lecturers were trying to explain. One student said, "I don't think they could relate to what they're teaching us," and another continued, "Whites relate more than us." One student explained:

Sometimes it's difficult because of the background that we have as Blacks. Like, the preschools we went to and they went to, the Whites, it's totally different. Like the first class, it was very confusing, like a science corner, water play, we did it in a way, but in a different way. You know, that thing made it different and that's why some of the Black students quit from Foundation Phase because they couldn't get acquainted or used to the terms used or understand ...

Another student said:

I went to a primary with just Black people. In a way, that could have disadvantaged me because you know when we have activities and people brainstorm and they say maybe a rhyme we used to say in preschool, there were a lot of things I didn't do in primary school. I don't remember a lot of what we did in primary school. I honestly felt like my education improved when I went to high school and now.

One student with a different experience commented:

The day care centre that I went to was really good. It was funded by a White person so it was kind of like the stuff we're doing here...It was a very good preschool for me, because as I look at the things l'm learning now, I think back, fantasy play was fantasy play outside. We would dress up; it was a huge yard, dress up, play. It was nice. We had a lot of toys. We would never run out of toys. 
There were tricycles, bicycles, anything that was supposed to be in a preschool, it was there. We had everything. For me, that was the best preschool.

In comparing their experiences from home with those that that were having in the early childhood education program the first year students described their home contexts:

Student 1: It just doesn't make sense to have all the things we have now. It's just a differently structured curriculum

Student 2: Because preschools in our Black communities are for business gain, teaching children, grooming them

Student 3: Yeah, it's about making money

Student 1: It's like bring children. They eat, they sleep, you come fetch them

Student 2: It's totally surprising. Children have to learn to write their names at preschool. Like the writing exercises, they're not doing that in preschools. It's just different.

\subsubsection{Differences in Language}

Not only were the experiences and examples used in the lectures different from those the students previously had, the language of instruction was not their first language and was more challenging than they had experienced in their secondary schooling and home communities. The academic demands of the language were particularly gruelling given the amount of reading that accompanied the modules required in their university studies.

Another thing I would like to suggest, like when we first came here and they were telling us which modules we have to do, we were forced, actually yeah, we were forced to do English because we had no other modules to do, so I think maybe it would be much better if they can offer, also add, African languages. Because, like English, it's so hard. Last year I failed all of them. I'm repeating all of them this year, 4 of them. So I think it will be much easier if they can add African languages in.

Yet another issue for the students was the preparation they needed to teach in the home languages of their future learners. The university curriculum offered few language 
options when the third year students began their studies; however, by the time the first year students enrolled, curricular changes had been instituted to provide students with more language options to study.

For foundation phase, they always teach us that for a child you teach a mother tongue, for like grade R, babies and toddlers. You communicate in English and use a little bit of the African like their mother tongue. So when we do like English, like the English we're doing now for FET...you can't do that for foundation phase. At least we can learn another language, maybe if they place me in Limpopo, I can teach in Sepedi and stuff instead of English because they don't, especially like kids from rural areas, they don't know English. You have to speak Zulu and try and teach them English. So we don't teach them like the English we're doing here. It's not relevant to what they're going to into at the foundation phase.

\subsubsection{Programmatic Forces}

These forces are defined as the official curriculum or programme as well as the hidden curriculum (Samuel \& Van Wyk, 2008: 141). This category can be regarded as external, as the curriculum is planned and implemented by lecturers.

\subsubsection{Experiences in the ECE Programme}

Within the classes themselves, students appeared to segregate themselves, sitting with peers of the same race in the lecture halls and working within same race groups during classroom activities. While their interactions suggested the groups had little impact on each other, one student did report:

You know, as I started coming here, all the negative attitude that has been in my mind about teaching has just gone away. I'm just seeing how White people are so enthusiastic about teachers, you know, just how can someone have so much passion? I thought I had passion; I don't have that much passion. But then it kind of inspires you, you know? 
Students were generally very positive about their experiences within the programme. They talked about faculty members promoting creativity and resourcefulness and offering interesting ideas and focusing on ways to motivate young learners.

With me I think it had definitely lived up to my expectations because we learn so much. Now we're learning about technology, we're doing maths. We're doing literacy. You feel like you're going to develop the child holistically. For my own personal development as well, my reading speed has become faster because we have to read. I feel I'm really getting my money's worth, this degree that I'm getting. If anything, I think the fourth year should be an honours - you do portfolios, practice teaching. I really feel our lecturers are really dedicated to the program. They make themselves available. They teach us until the last day of the term.

Practical teaching that came at the beginning of the second and third years of the programme, were seen as valuable. The first practical occurred at the beginning of the second year in a preschool setting and was typically completed in the home community. The second practical, at the beginning of the third year, was done in a primary grade in Pretoria and was more closely supervised by the ECED faculty.

And then the practicals I did this year really changed me I had to focus. I knew a lecturer was coming to observe me so I knew I had to be up to standard. So the theory that they taught me from first year up until my second year really did help me with my practicals and that made my practicals much easier than my second year practicals. Because there wasn't as much expected of me...so my third year practicals really changed me and I think I'm going to be a great teacher.

But students were concerned with how they would be able to translate the practices they had learned about in resource rich contexts into their future classrooms.

And it's quite challenging, because now, what we're getting here, it's quite good. It's really excellent. But then you wonder, if you're going back, into the practical world where you're going to teach, I'm preferring grade one to go and teach in black schools because I want to improve but then it comes again like, how are you going to implement these, the resources, it's a government school to start with and they going to think you want to be special. You want an overhead 
projector in your class, they don't have it. You know you have to buy things on your own now.

\subsubsection{Contextual forces}

These are explained as "the macro-environment of educational transformation" and "can be more site specific" (Samuel \& Van Wyk, 2008:141). In this study the contextual force refers to the financial impact that the programme has on the Black student. According to a study done by Breier (2010:669) on the reconceptualisation of the role of finances in higher education, "finances play a very important role for those in the lower socioeconomic groups, not only in choice of institution and study programme, but also in leading to premature departure after registration, either because of unexpected financial demands or because the student underestimated the full cost of higher education".

\subsubsection{Costs}

There were definite costs that were both financial and personal associated with the programme. The limited financial resources of the Black students meant that they had to learn to balance the funds they might receive from home and the bursaries that went towards tuition, books, accommodation, and food. ECE programme costs associated with the supplies for creating learning resources and laminating and transport to practicals often stretched students' limited budgets to the limits. Although students looked for ways to economize by skipping meals, sharing books, or walking, they were aware that their White peers had greater access to these things and gained "privileges" in terms of higher marks or arrived at pracs refreshed and ready to start the school day. One student, in explaining the limited extent of her bursary, said:

They [the government] are giving us money. And then first year we never had a change. And then second year, they gave us money for textbooks. It's not enough for all the books, but at least we can buy some of the books. We made copies with the chapters that they want because I can't afford the books and then I make copies for chapters that I'm going to use maybe for JGS book I make 4, 3 chapters and then l'll buy some of the books like for JBN and stuff. 
While they followed suggestions from lecturers to recycle materials as a way to save funds, students could not help compare their finished products with those of their peers.

And then for medias that I have to use, especially music, it was fun. They showed us how to do it with tin. I had to do drums and I did nice things. But then it's also like...when you have to submit your assignment, like learners have bought some of the stuff and it's nice. Obviously you can't compare your media with another student because you can see I made my own stuff and she bought it and stuff. And then it's nice and she will get the full mark for the $100 \%$. It's nice and you love it, so it also comes back that I have to make my own stuff. And we're trying to be creative, we never did those things at school so now we're still learning.

Another student went on to point out the personal cost to her own esteem as she reflected on what other students were able to do because they had greater financial resources.

I can't have money to buy the cookie monster [puppet] and then the finger puppets. They're expensive. And so is last year, when we're doing music... they also said the same thing, that you should make your own stuff and we were like recycling, the thing was recycle. And then like the Whites and the Indians, they came with their nice stuff which they bought and then they display them in the library and we feel like why did they make this thing because they said that we should do it ourselves so you feel small.

The contradiction between being creative in using recycled materials and being able to buy new materials was not lost on the students. While one student pointed out:

One thing that I like about the way that the lecturers rate is through creativity, whether the material is good enough, it's just how much effort you put into doing the project, they recognize the effort and your own creativity, initiative. They do give you marks for presentation, but they also focus much more on your creativity. 
Another student said

I think it's not fair because you have to be creative. They are telling us to create our own stuff but some bought the stuff and you find that it's nice and they'll give the learners the full marks. But then I think it's not fair because they can't compare the 2. They just have to look at mine and then give me a mark, Ok this one, at least she made it herself.

Compounding the challenge of purchasing supplies for their learning resources, students were unsure of where to get materials that the white students typically considered part of the supplies early childhood people had readily available. And yet, the students recognized the value in creating durable learning materials for their lessons and for the future.

It's actually more expensive than other courses because we have a lot of assignments to do, practical stuff to do, a lot of resources to do because during our teaching prac they expect us to have resources, resources, resources. So throughout first year until now we should have enough resources and we still have to make other resources, whereas the other phases, they just go into the classes and teach.

Other supplies that were associated with the ECED modules included copying costs and access to computers. Students tried to address these problems on their own to maximize their performance.

Especially for foundation phase...because sometimes we do a lot of printing. We have to buy colour boards, we have to print. And then you find you have to print on colour, 5 rand each copy. Yeah, we don't have those things. So, we don't have computers at home, even if maybe we have an assignment because we had a lot of assignments these holidays. Then I was thinking, I'm not going to go home, I'll just go home for the weekend and come back and do my work. If the bursary can provide like more money then we can try to buy some stuff that we don't have because we know that we need to have those things, like printers, computers or laptops or just a computer. If we can have those things I can do my work at home. 
Another cost for students was associated with travel from campus to the teaching practicals and for service learning experiences that were incorporated into courses created special challenges for the students. Since none of them had cars, the students had to pay for transport or walk. Few students with cars offered to help out and the students didn't indicate that they asked for rides. The students did say that when they applied for their practicals for the beginning of their third year, that the person responsible for placements attempted to locate them in schools that were closer to their residence halls. Still, the students expressed concerns and suggested that the university provide transport:

because you can't go to Sunnyside every day. And it's not safe. And you go to school, you arrive there, tired, sweating. You come back, it's the same thing. And the assignments that they give, they give us most of the time it's practical work. Like now we have to go to school for 20 hours and look at the weather now. I remember last week, we went there ... And last week it was raining. I remember when we went there to make the appointment, when we came back we were wet, so I don't think it's fair. Maybe I think it would be better if they can like, the lecturers provided learners for us and they came here and we teach them. I think it would be fair like that because we don't have cars and we can't afford them anyway if we wanted to buy. So I don't think it's fair on us.

\subsubsection{Institutional Forces}

This category refers to "the specific characteristics of teacher education institution's expectations, their values and goals [which] generate particular conceptions of a professional teacher" (Samuel \& Van Wyk, 2008:141).

\subsubsection{Conflicting concepts of teaching/learning}

As students contrasted their experiences as learners at home and the quality of education in their home schools with their experiences in the Early Childhood programme, they noted the differences in teachers' training and the subsequent expectations for learners. They began to realize that their new experiences were 
providing new possibilities for their home communities and took the responsibility for returning home as change agents seriously:

With us, they use to teach us, you know, something that doesn't even benefit the child's intellectual capacity. That really breaks our heart and I'm like, asking myself a question. What happened to foundation phase teachers? Are they there? But funny enough, I just realized that they haven't got their proper training. The teacher that is teaching those grade one children, I know her. I know she didn't go to varsity. She was just teaching a preschool and they felt they wanted to start a grade $R$ so they said, come teachers we need you. There is no proper training yet. But I feel if we are here, but l'm still wondering, if this particular university is having so much less percentage Black students in ECE, how much percentage, really, because only few White people will want to go and teach in Black schools? So it's not balancing in a way because yes, White education, like White learners, what can I say, multiracial schools have better education than government Black schools, so it's not balancing in a way. I don't know.

\section{DISCUSSION}

The Force Field Model provided four different categories which influenced the experiences of Black students in the ECE programme. The "biographical force" is the only category which represents an internal force, at it originates from the Black student's cultural background. The rest of the categories can be classified as external forces as these exert an influence from outside the individual. Samuel and Van Wyk (2008) furthermore distinguish between a pull- and push effect, which in the context of this study may persuade a student to move in a certain direction (decide to enrol in the ECE programme), or may sway the student in another direction (rather opting for another phase or another field).

Considering the "biographical forces", their schooling experiences (lived experiences) determined how Black students perceived the programme. Depending on their backgrounds, some participants perceived these forces as a push-effect ("Sometimes it's difficult because of the background that we have as Blacks. Like, the preschools we went to and they went to, the Whites, it's totally different") while another participant 
experienced this as a pull-effect: "The day care centre that I went to was really good. It was funded by a White person so it was kind of like the stuff we're doing here...It was a very good preschool for me...". Language was also perceived as a push-effect by all participants, as all of them struggled with English.

"Programmatic forces", which refers to how Black students perceived the programme, had a pull-effect, and hence were positive. Students appreciated the learning content, passion of their White peers and dedication of the lecturers and also regarded the value of practice teaching in a positive light.

A definite push-effect was detected in the financial aspect of the ECE programme. Financial supports intended to equalize the differences between Black and White students were helpful, but limited in the extent to which they addressed the costs of the early childhood programme. Even though all the students received bursaries designated for tuition and books, accommodations, and meals, they repeatedly reported that the funds available to them were inadequate to cover all their expenses and additional funds from family members were limited. To meet those challenges students became resourceful in sharing books, securing used materials, and even skipping meals to fund the costs associated with their assignments.

Being able to study at an institution with a good reputation and international ranking, holds a definite appeal to Black students (Bitzer, 2010). The "institutional force" has a strong pull-effect, as quality education is regarded highly. Participants mentioned that they proverbially got to know 'another world', which was far removed from what they were used to. Our participants' stories reflected the tensions they experienced as they saw in their ECE classes and practicums an "idealized" educational setting with small class sizes, ample resources and learning materials, and instructional technologies that were unavailable in their own schools. The stark contrast between what they learnt at university and the reality of their home circumstances, made them sad, but also made them realize the importance of a formal qualification in ECE. 


\section{CONCLUSION}

How do we change a system that seems to be resistant to the fundamental changes necessary to prepare our Black students? From the perspectives of the students we interviewed, making resources available for the learning modules and having greater access to affordable text books and materials for assignments are a starting point. But lecturers must also take the responsibility to critically reflect on their own teaching and module content as to focus on recruiting more Black students into the programme. Competing departmental and university priorities on research productivity and programme revision, large class sizes, and heavy teaching loads take the attention of the Department of ECE away from a focus on such a small population of students.

So what do we as lecturers do to change a programme that continues to fill ECE lecture halls with students, $99 \%$ of whom are white females? It means we must actively recruit students from across the country, provide adequate financial support, offer flexibility in keeping up with students as they enter and exit the programme, and use their input as we attempt to employ culturally relevant teaching methodologies for them and ourselves. It also means that we need all of our students, regardless of their race or culture, to develop the knowledge, skills, and attitudes that enable them to teach learners who are unique individuals with diverse ways of learning and understanding their world.

We must begin to appreciate the wealth of knowledge that all our students bring into the Early Childhood Education programme. As we listened to the stories the students shared, we began to appreciate the strengths that they brought to the programme in new ways. The insights we gained have led us to reconsider ways to build relationships with all students so that we can encourage and hear their voices and create spaces for their perspectives to be reflected in the modules that we teach. 


\section{BIBLIOGRAPHY}

Arends, F. and Phurutse, M. (2009) Beginner teachers in South Africa: School readiness, knowledge and skills. Cape Town: HSRC Press.

Basit, T.N., McNamara, O., Roberts, L., Carrington, B., Maguire, M., \& Woodrow, D. (2007) 'The bar is slightly higher': the perception of racism in teacher education, Cambridge Journal of Education, 37(2): 279-298.

Botha, L., Du Plessis, A., \& Menkveld, H. (2007) 'n Ontleding van deurvloeikoerse aan die universiteit van Stellenbosch. Stellenbosch: Universiteit van Stellenbosch.

Brüssow, S. (2007) A learning facilitation to enhance academic skills development among underprepared learners in South African higher education. Bloemfontein: University of the Free State.

Crosser, M. (2009) Studying ambitions: Pathways from Grade 12 and the factors that shape them. Cape Town: HSRC Press.

Davis, M., Dias-Bowie, Y., Greenberg, K., Klukken, G., Pollio, H.R., Thomas, S.P., \& Thompson, C.L. (2004) "A fly in the buttermilk": Descriptions off university life by successful Black undergraduate students at a predominantly White south-eastern university. Journal of Higher Education, 75(4): 420-445.

De Beer, M. (2010). Collaboration recommendations for culturally relevant teaching and development in higher education. Consulted June 4, 2010, from http://www.cepd.org.za/files/pictures/SUBMISSION-COLLABORATIONFOR CULTURALLYRELEVANTTEAHINCANDDEVELOPMENTINHIGHEREDUCATION_0pd $f$

Denzin, N.K. \& Lincoln, Y.S. eds. (2000) Part II: Paradigms and perspectives in transition. In N.K. Denzin and Y.S. Lincoln eds., Handbook of qualitative research $\left(2^{\text {nd }}\right.$ ed).:156-162. Thousand Oaks, CA: Sage.

Department of Education (May 2001) Education White Paper 5 on Early Childhood Education: Meeting the challenge of early childhood development in South Africa. Pretoria. 
Epstein, K.K. (2005) The Whitening of the American teaching force: A problem of recruitment or a problem of racism? Social Justice, 32(3): 89-102.

Everatt, D. (2002) From urban warrior to market segment? Youth in South Africa 19902000. Development Update, 3(2): 1-26.

Fraser, W., \& Killen, R. (2005) The perceptions of students and lecturers of some factors influencing academic performance at two South African universities.

Perspectives in Education, 23(1): 25-40.

Gbadamosi ,G., \& De Jager, J. (2009) 'What you see is what you get': Service quality, students'

perceptions and satisfaction and South African universities. South African Journal of Higher Education, 23(5): 877-893.

Giles, M.S., \& Hughes, R.L. (2009) CRiT waling race, place and space in the academy. International Journal of Qualia5tive Studies in Education, 22(6): 687-696.

Gomez, M.L. (1997) Narrative inquiry, in C.A. Grant \& G. Ladson-Billings (eds), Dictionary of multicultural education. Phoenix, AZ: The Oryx.

Gregory, S.T., \& Hill, O.O. (2000) Improving learning outcomes for at-risk multicultural community college students. Oxford: University Press of America.

Kornfield, J. (1999) Sharing stories: a study of African American students in a predominantly white teacher education program. Teacher Educator, 35(1): 19-40.

Ladson-Billings, G. (2001. Crossing over to Canaan. San Francisco: Jossey-Bass, Inc. Ladson-Billings, G.J. (1999) Just what is critical race theory and what's it doing in a nice field like education, in L. Parker, D. Deyhele, S. \& Villenas (eds) Race is...race isn't: Critical race theory and qualitative studies in education. Boulder, CO: Westview Press.

Ladson-Billings, G. (1994) The dreamkeepers. San Francisco: Jossey-Bass, Inc.

Landsman, J., \& Lewis, C. eds (2006) White teachers/diverse classrooms: A guide to building inclusive schools, promoting high expectations, and eliminating racism. Sterling, 
VA: Stylus.

Meacham, S.J. (2000) Black self-love, language, and the teacher education dilemma: The cultural denial and cultural limbo of African American preservice teachers. Urban Education, 34(5): 571-596.

Milner, H.R. (2008) Critical race theory and interest convergence as analytic tools in teacher education policies and practices. Journal of Teacher Education, 59(4): 332-346.

National Education Association. (2002) Help wanted: Minority teachers. Tomorrow's teachers.

Washington, DC: Author.

NCES. (2010). The condition of education 2010. Washington, DC: US Department of Education Institute of Education Sciences. Retrieved June 28, 2011, from http://nces.ed.gov/pubsearch/pubsinfo.asp?pubid=2011033

Planty, M., Hussar, W., Snyder, T., Kena, G., KewalRamani, A., Kemp, J., Bianco, K., \& Dinkes, R. (2009). The condition of education 2009. National Center for Education Statistics, 22, : 24, 58, 94-95, 98-103.

Pollack, M. (2008) Everyday antiracism: Getting real about race in school. New York: The New Press.

Robinson, J.J., Paccione, A., \& Rodriguez, F. (2003) A place where people care: a case study of recruitment and retention of minority-group teachers. Equity \& Excellence in Education, 36(3): 202-212.

Santoro, N. (2007) 'Outsiders' and 'others': 'different' teachers teaching in culturally diverse classrooms. Teachers and Teaching: theory and practice, 13(1): 81-97.

Sedlacek, W.E. (1999) Black students on White campuses. 20 years of research. Journal of College Student Development, 40(5): 538-550.

Seidman, I. (2006) Interviewing as qualitative research: A guide for researchers in education and the social sciences $\left(3^{\text {rd }}\right.$ ed.). New York: Teachers College Press.

Sennet, J., Finchilescu, G., Gibson, K., \& Strauss, R. (2003) Adjustment of Black students at a historically White South African university. Educational Psychology, 23(1): 107-116. 
Stanton-Salazar, R., Vásques, O.A., and Mehan, H. (2000) Re-engineering academic success through institutional support. In S.T. Gregory (ed.), The academic achievement of minority students: Perspectives, practices and prescriptions. Oxford: University Press of America.

Steyn, M.G., Harris, T. T., \& Hartell, C. G. (2011) Where are the foundation phase teachers for our children? Black students' perceptions. South African Journal for Higher Education, 25(3).

Villegas, A.M., \& Davis, D.E. (2007) Approaches to diversifying the teaching force: attending to issues of recruitment, preparation, and retention. Teacher Education Quarterly, 137-147.

Walker, M. (2005) Rainbow nation or new racism? Theorizing race and identity formation in South African higher education. Race Ethnicity and Education, 8(2):129146. 